\title{
Community Acceptability of Voluntary Medical Male Circumcision (VMMC) as a Strategy in the Fight against the Spread of HIV and AIDS among Residents of Homa-Bay County Kenya
}

\author{
Article by Albert Ngetich ${ }^{1}$, Benard O. Abongo ${ }^{2}$, Gordon Okomo ${ }^{3}$ and Collins Ouma ${ }^{4}$ \\ ${ }^{1}$ School of Public Health, Texila American University, Nicaragua \\ ${ }^{2}$ Faculty of Science, National University of Lesotho, Lesotho \\ ${ }^{3}$ Directorate of Health Services at the Ministry of Health, Homa Bay County, Kenya \\ ${ }^{4}$ School of Public Health and Community Development, Maseno University, Kenya \\ E-mail: ngetich.albert@gmail.com ${ }^{1,}$ bo.abongo@nul.ls ${ }^{2}$, okomogordon@hotmail.com ${ }^{3}$, \\ collinouma@yahoo.com ${ }^{4}$
}

\begin{abstract}
Background: Voluntary medical male circumcision (VMMC) reduces female-to-male transmission of HIV by about $60 \%$ leading to the global WHO and UNAIDS recommendation of VMMC to men. A traditionally non-circumcising Luo ethnic community predominantly occupies Homa-Bay County in western Kenya where the uptake of VMMC as an intervention for prevention of HIV acquisition has been low. Community dialogue is a participatory communication process of sharing information aimed at reaching a common understanding and workable solution. The current study documented the baseline status on the acceptability of uptake of VMMC and access to voluntary counselling and testing (VCT) among residents of Homa-Bay County, Kenya prior to intervention (community dialogue).

Methods: Males of Luo ethnic group, uncircumcised and aged 18-49 years drawn from 419 households were recruited. Baseline information (before intervention) were collected to capture the acceptance of VMMC, circumcision status and testing for HIV in the population. Structured and semi-structured questionnaires were used for data collection.

Results: Analysis showed that in Ndhiwa, Rachuonyo North and Suba South Sub-counties, $54.9 \%, 84.1 \%$ and $69.8 \%$, respectively, had accessed VCT, while 3.5\%, $0.7 \%$ and $10.8 \%$, respectively had undergone VMMC. The proportions of those who accessed VCT services were significantly higher $(P<0.0001)$ while the proportions of those who had undergone VMMC were significantly lower $(P<0.0001)$ across the three sub-counties.

Conclusion: These results demonstrate that even though majority access VCT services to know their HIV status, significantly few men decide to undergo VMMC. This revealed a decreased acceptability of this service in Homa-Bay County prior to the intervention.
\end{abstract}

Keywords: VMMC, VCT, community acceptability, HIV and AIDS.

\section{Introduction}

Male circumcision, the surgical removal of all or part of the foreskin of the penis is one of the oldest and most common surgical procedures worldwide. Recently it has been reported that medical male circumcision can significantly reduce (but not eliminate) men's risk of acquiring HIV through heterosexual vaginal sex (Bailey et al., 2007). In Kenya, there has been an increased HIV prevalence over the years. For example, HIV prevalence among children aged 18 months to 14 years was $0.9 \%$, representing approximately 101,000 HIVinfected children. HIV prevalence decreased with increasing age among children, from $1.6 \%$ among children aged 18 months to 4 years, $0.8 \%$ among children aged 5-9 years, and $0.6 \%$ among children aged 10-14 years (KAIS, 2012). In 2013, the national HIV prevalence for Kenya was estimated to be $6 \%$ for those aged 15-64 years (KAIS, 2014). Stratified by regions, Nyanza recorded the highest HIV prevalence of $15.1 \%$ with rural and urban areas in Nyanza having HIV prevalence of $13.9 \%$ and $18.3 \%$, respectively. Amongst all the counties in Nyanza, Homa-Bay is currently ranked as that with the highest HIV cases with an adult 
HIV prevalence of $25.7 \%$ and a total of 191,840 children living with HIV with an annual newly HIV-infected children in Homa-Bay standing at 2,700 (KAIS, 2014). The current number of children in need of ART stands at 16,500 yet only 2,755 children in Homa-Bay County receive ART. This implies that a total of $83 \%$ of children living with HIV in HomaBay County and who are currently in need of ART, are not under treatment.

Despite these statistics showing that the region is hard hit by HIV and AIDS scourge, residents of Homa-Bay County, majority of whom are drawn from the Luo ethnic group, by virtue of their culture, do not practice male circumcision with a significantly lower uptake of VMMC recorded in this region. This low uptake of VMMC in the region reduces the chances of the males from health benefits associated with VMMC. Previous studies have associated transactional sex among fishing communities living along L. Victoria. Due to the nature and context of the sexual intercourse, sex typically occurs in a hurried manner, often without preparation or protection. Thus, by engaging in a web of these relationships, conducted in contexts that compromise their ability to practice safer sex, men and women in these fishing communities are at increased risk of HIV (Kwena et al., 2012). Given that Homa-Bay County falls within the Lake Victoria basin the same practice is manifested in the region potentially leading to uncontrolled spread and consequently high prevalence of HIV.

Acceptability has become a key consideration in the design, evaluation and implementation of healthcare interventions. Many healthcare interventions are complex in nature; for example, they can consist of several interacting components, or may be delivered at different levels within a healthcare organization (MRC, 2008). Acceptability thus is a multi-faceted construct that reflects the extent to which people delivering or receiving a healthcare intervention consider it to be appropriate, based on anticipated or experienced cognitive and emotional responses to the intervention. In the context of the current study, acceptability was defined as the potential of the uncircumcised male participants to consider and access the interventions available globally to prevent the spread of HIV infection: voluntary medical male circumcision (VMMC). Since Voluntary Counseling and Testing is a supplementary intervention during $\mathrm{VMMC}$, the study also assessed access to this service alongside VMMC.

Community dialogue is an interactive participatory communication process of sharing information between people or groups of people aimed at reaching a common understanding and workable solution. Since it has been previously established in other settings that community dialogue can produce changes in three of the underlying structural factors of HIV: gender attitudes, gender roles, and HIV stigma and further support positive changes in other factors associated with HIV infection, including HIV prevention knowledge, discussion of HIV between sex partners, and having one sex partner (Figueroa et al., 2016), the current study determined the acceptability of voluntary medical male circumcision (VMMC) as a strategy in the fight against the spread of HIV and AIDS among residents of Homa-Bay County, Kenya.

\section{Materials and methods}

Study site and participants. The study was carried out in Homa-Bay County western, Kenya. A longitudinal study design was adopted for the study whereby uncircumcised males of Luo ethnic group aged 18-49 years and residents of Homa-Bay County were recruited into the study. Baseline information was collected to capture the acceptance of VMMC and factors affecting acceptability of VMMC and access to VCT; circumcision status and testing for HIV. Only those who had not circumcised and had never undertaken HIV test were recruited into the study and a questionnaire used to collect baseline data.

Sample size calculation: A representative sample size using the infinite formula (where the population is greater than 50,000) (Godden, 2004):

$\mathrm{SS}=\left[\mathrm{z}^{2} \times \mathrm{p} \times(1-\mathrm{p})\right] \div \mathrm{c}^{2}$

Whereby

- $\mathrm{SS}=$ Sample Size 
- $\mathrm{Z}=\mathrm{Z}$-value A (e.g., 1.96 for a 95 percent confidence level)

- $\mathrm{P}=$ Percentage of population picking a choice, expressed as decimal

- $\mathrm{C}=$ Confidence interval, expressed as decimal (e.g., .04 = +/- 4 percentage points).

A Z-values (Cumulative Normal Probability Table) represent the probability that a sample will fall within a certain distribution. Taking the value of $\mathrm{z}$ to be $1.96, \mathrm{p}$ to be 0.5 and $\mathrm{c}$ to be 0.04. On substitution:

$$
\text { New SS }=\frac{\text { SS }}{1+\frac{(\text { SS }-1)}{\text { Population }}} \quad-0.0016
$$

In this case population is 1250 households. Therefore $S S=600 \div[1+(600-1) \div 1250]=$ 405 households. As such, a minimum sample size of 405 was required.

\section{Sampling technique}

Using a Community Health Worker-generated household register, a systematic random sampling of households was done at a sampling interval of 3 (derived from total households/targeted households i.e. 1250/405=3.0). To be considered during the systematic random sampling of households within the villages making up Homa-Bay County, male residents had to be aged 18-49 years. Following collection of baseline data, community dialogue sessions were done by recruits drawn from every village and who were familiar with the terrain and constitution of the households.

\section{Validation of data}

Prior to the use of data collection tools, they were piloted in the nearby Migori County. Migori County has the same set up as Homa Bay County and thus provided the best location for piloting. Following piloting, the tools were adjusted for clarity and consistency. In addition, analyses and verification of results was done by two independent individuals to take care of inconsistency in analyses and presentation of results.

\section{Ethical considerations}

Scientific and ethical approval was sought from Maseno University's Ethics Review Committee (MUERC). Additional approval was sought from the Homa-Bay County, Director of Health. Informed consent was obtained from study participants prior to inclusion in the study. Participation into the study was on voluntary basis. Consent documents and questionnaires were identified only by unique identification numbers and the names of the participants do not appear in the final data files.

\section{Data analyses}

Descriptive statistics were used to analyze continuous variables. Chi-square test was used to establish proportionality. $P$-values $\leq 0.05$ were considered statistically significant.

\section{Results}

\section{Demographic characteristics of the study participants}

A total of 419 respondents were drawn from three sub-counties within Homa-Bay County. The distributions of the 419 respondents were as follows: Ndhiwa Sub-county were 142 (33.9\%), Rachuonyo North were 138 (32.9\%) and Suba South were 139 (33.2\%). The data that follows are henceforth stratified as per these sub-counties. Table 1 presents the sociodemographic and socio-economic characteristics of the study participants as stratified into these 3 sub-counties. In the three different sub-counties, majority were married i.e. $69.7 \%$ in Ndhiwa, 58\% in Rachuonyo and 64.7\% in Suba Sub-counties. The proportions of those under the different marital status $(P=0.041)$ were significantly different. Likewise, the proportions of those belonging to different religious groups $(P=0.001)$ were different since there was a higher proportion of those in Other Christians in Ndhiwa (38\%) and Rachuonyo (36.2\%) 
while Roman Catholic was highest in Suba South (42.4\%). Majority of the respondents were either farming or casual labourers across the different sub-counties and the proportions of those in different categories of professions were were significantly different across the subcounties $(P<0.0001)$, with the monthly income $(P=0.004)$ also varying significantly across the 3 different counties. However, those resident in rural versus urban set-ups were comparable $(P=0.071)$. These might imply that the set-up in the different sub-counties in Homa-Bay County is generally different socio-demographically and socio-economically.

Community acceptability of voluntary medical male circumcision (VMMC) as a strategy in the fight against the spread of HIV and AIDS among residents of Homa-Bay County Kenya: In order to determine community acceptability of voluntary medical male circumcision (VMMC) as a strategy in the fight against the spread of HIV and AIDS among residents of Homa-Bay County Kenya, access to VMMC and VCT services were evaluated across the three sub-counties. Results revealed that as much as majority had accessed VCT services within the different sub-counties, very few respondents had actually undergone VMMC. For example, for Ndhiwa sub-county, 54.9\% accessed VCT while only $3.5 \%$ had undergone VMMC. For Rachuonyo North, 84.1\% accessed VCT while only $0.7 \%$ had undergone VMMC and finally for Suba South, 69.8\% had accessed VCT services while only $10.8 \%$ had undergone through VMMC. The proportions of those who accessed VCT were significantly higher across the three sub-counties $(P<0.0001)$ while the proportions of those who did not undergo VMMC across the three sub-counties were significantly lower $(P<0.0001)$ (Table 2). These results collectively demonstrate that as much as majority access VCT services to know their HIV status, very few opt to undergo VMMC thus demonstrating a decreased acceptability of this service in Homa-Bay County.

Access to VMMC, VCT and socio-demographic characteristics in Homa-Bay County: Since acceptability and access to VMMC and VCT could be affected by the sociodemographic factors within the population, those who accessed both VMMC and VCT or any one service were further stratified according to their socio-demographic characteristics. Results revealed that for VCT, the proportions were comparable for those who accessed versus those who did not access for marital status $(P=0.228)$, religion $(P=0.182)$, occupation $(P=0.163)$, monthly income $(P=0.234)$ while for place of resident $(P=0.791)$. The same pattern was shown for VMMC for marital status $(P=0.328)$, religion $(P=0.375)$, occupation $(P=0.905)$, monthly income $(P=0.054)$ while for place of resident $(P=0.313)$. Since distance to the facilities and age of sexual debut can affect access to the VCT and VMMC services, the current study assessed the distribution of participants who accessed these services against the distances and age of sexual debut (Table 3). Results reveal that 21 (100\%) individuals who were residing at a distance of $0-10 \mathrm{~km}$ to the VMMC facility actually underwent VMMC. Majority of those who did not undergo VMMC (95.7\%) were also residing at a distance of $0-10 \mathrm{~km}$. The proportions of those who underwent VMMC and those who did not as stratified by distance were comparable $(P=0.817)$. The proportions of those who accessed VCT $(P=0.892)$ and VMMC $(P=0.465)$ based on their age to sexual debut was also statistically insignificant. However, those who accessed VCT were significantly higher in those who lived $0-10 \mathrm{~km}$ to the facility than any other group $(P=0.048)$. Collectively, these results demonstrate that distance to the facility only affect access to VCT but not VMMC. Age to sexual debut does not affect access to VCT or VMMC services.

\section{Discussion}

The current study was designed to determine community acceptability of voluntary medical male circumcision (VMMC) as a strategy that can be used to fight the spread of HIV and AIDS among residents of Homa-Bay County Kenya. Voluntary medical male circumcision (VMMC) has been shown to reduce the risk for heterosexually acquired HIV among men by approximately 60\% (CDC, 2013; Clinics, 2007; Kosnett et al., 2007; Program, 2013). Despite the massive scale-up of VMMC in non-circumcising communities in Kenya, uptake of VMMC has been low (63\%) among men aged $\geq 25$ years as compared to 
men aged 15-24 years (72\%) (Galbraith et al., 2014). However, acceptability of VMMC in Homa-Bay County commonly inhabited by the non-circumcising Luo community remained unknown. We therefore assessed the community acceptability of the VMMC. Since most of the facilities provide both VCT and VMMC services, we also assessed access to VCT services in the same community.

Based on the current knowledge, this is the first report to look at acceptability of VMMC by males resident in such a lakeshore setting - Homa-Bay County, Kenya. However, it would be critical to point out these early potential limitations to the current study. Raw data were not easily available, and the available number of observations sometimes limited the statistical analysis. We could not have well appreciated the duration of pre- or post-test counseling sessions in the VCT prior to performance of the VMMC. Many factors associated with the region itself, the culture of the population, the perception of the risks, the motivation of the counselors, and the level of discrimination against HIV-infected persons could not be taken into account.

The current study demonstrated that only $5.01 \%$ (21/419) had undergone through VMMC. Such prevalence is comparable with that of other studies conducted in China (Luo et al., 2011). It is much lower than that of the U.S., Republic of Korea and Philippines (UNAIDS, 2007). Acceptability of VMMC and interventions are likely to differ when interventions are implemented in a public health programme. In regions where a particular effort in implementing VMMC programmes had been made, overall acceptability of HIV testing in the population is usually high. In many developing countries, such as in Kenya, VMMC is always offered alongside VCT services. However, the possible benefits of VCT (such as medical and psychosocial management) are limited or non-existent, and fear of having to cope with the result is usually common (Sahlu et al., 1998). In the current study, the respondents were more comfortable accessing VCT services but not undergoing VMMC. These observations underscore the fact that in these study populations, males, due to increased reported risks along Lake Victoria regions have made deliberate attempts to access VCT. However, there was an enhanced lag in undergoing VMMC possibly as a result of combined factors, which definitely were not related to the socio-demographic characteristics of the study participants.

The current study also demonstrated that distance to the facility only affect access to VCT but not VMMC. Age to sexual debut does not affect access to VCT or VMMC services. However, the reasons for lack of acceptability with a focus on reasons for not accessing, source of information on VCT or VMMC, discussions with spouse, partner approval or financial hindrances were documented. The following were the order of responses for reasons for not accessing VCT (8.6\% said unfriendly staff; $7.0 \%$ said they had other reasons while $1.6 \%$ said it was not applicable) and VMMC [20.9\% said they feared stigma, $19.6 \%$ said unknown side effects, $18.1 \%$ said that they feared interferences with sexual desires, $10.6 \%$ said it was not convenient, $5.5 \%$ indicated the duration of service was long, $5.0 \%$ indicated spousal refusal, $3.8 \%$ cited costs/affordability issues, $2.5 \%$ indicated unfriendly staff, $2.3 \%$ said Luo culture does not allow, $2.0 \%$ were ignorant about it while several others cited faith not allowing $(0.8 \%)$, dislike VMMC $(0.8 \%)$, too old to perform it $(0.5 \%)$, penis too short to undergo VMMC $(0.5 \%)$ and several other myths]. Similarly, previous studies also showed significant associations between perceived side effects and acceptability of VMMC (Brito et al., 2009; Feng et al., 2010). Testimonials made by peers who had taken up VMMC on potential positive effects of VMMC for their sexual performance and mildness of side effects were potentially useful.

In contrast, only a minority of the participants perceived that high cost was involved for taking up VMMC. Therefore, financial subsidy for County governments (and even nationally) to take up VMMC seems unnecessary, making future VMMC implementation programs more sustainable. 
DOI: $10.21522 / \mathrm{TIJPH} .2013 .06 .03 . A r t 002$

ISSN: $2520-3134$

\section{Conclusion}

The data from the baseline survey revealed that VCT as opposed to VMMC was more acceptable to the males respondents resident in Homa-Bay County, Kenya.

\section{Acknowledgments}

Much appreciation goes to Maseno University Ethics Research Committee (MUERC) members for approval of the study and the Director of Health, Homa-Bay County, for his authorization to carry out the study in Homa-Bay County. I extend my sincere thanks to one and all of the research team at Homa-Bay County and the study participants whose help was fundamental in the completion of this document.

\section{References}

[1].Bailey, R.C., Moses, S., Parker, C.B., Agot, K., Maclean, I., Krieger, J.N., Williams, C.F., Campbell, R.T., and Ndinya-Achola, J.O. (2007). Male circumcision for HIV prevention in young men in Kisumu, Kenya: a randomised controlled trial. Lancet 369, 643-656.

[2].Brito, M.O., Caso, L.M., Balbuena, H., and Bailey, R.C. (2009). Acceptability of male circumcision for the prevention of HIV/AIDS in the Dominican Republic. PLoS One 4, e7687.

[3].CDC (2013). Adult Blood Lead Epidemiology and Surveillance (ABLES). Cincinnati, OH: US Department of Health and Human Services, CDC, National Institute for Occupational Safety and Health; 2013. Available at http://www.cdc.gov/niosh/topics/ables/description.html.

[4].Clinics, A.o.O.a.E. (2007). Medical management guidelines for lead-exposed adults. Washington, DC: Association of Occupational and Environmental Clinics; 2007. Available at http://www.aoec.org/documents/positions/MMG_FINAL.pdf.

[5].Feng, N., Lu, F., Zeng, G., Nan, L., Wang, X.Y., Xu, P., Zhang, J.X., and Zhang, S.E. (2010). [Acceptability and related factors on male circumcision among young men with Yi ethnicity in one county of Sichuan province.]. Zhonghua Liu Xing Bing Xue Za Zhi 31, 281-285.

[6].Figueroa, M.E., Poppe, P., Carrasco, M., Pinho, M.D., Massingue, F., Tanque, M., and Kwizera, A. (2016). Effectiveness of Community Dialogue in Changing Gender and Sexual Norms for HIV Prevention: Evaluation of the Tchova Tchova Program in Mozambique. Journal of health communication 21, 554-563.

[7].Galbraith, J.S., Ochieng, A., Mwalili, S., Emusu, D., Mwandi, Z., Kim, A.A., Rutherford, G., Maina, W.K., Kimanga, D.O., Chesang, K., et al. (2014). Status of voluntary medical male circumcision in Kenya: findings from 2 nationally representative surveys in Kenya, 2007 and 2012. Journal of acquired immune deficiency syndromes 66 Suppl 1, S37-45.

[8].KAIS (2012). National AIDS and STI Control Programme. Kenya AIDS Indicator Survey 2012: Final Report. Nairobi, Kenya: NASCOP, 2014.

[9].Godden, B. (2004). Sample size formulas. Available at: http://williamgodden.com. Accessed 30th December, 2017.

[10]. KAIS (2014). Kenya AIDS Response Progress Report: Progress Towards Zero, National AIDS Control Council.

[11]. Kosnett, M.J., Wedeen, R.P., Rothenberg, S.J., Hipkins, K.L., Materna, B.L., Schwartz, B.S., Hu, H., and Woolf, A. (2007). Recommendations for medical management of adult lead exposure. Environmental health perspectives $115,463-471$.

[12]. Kwena, Z.A., Bukusi, E., Omondi, E., Ng'ayo, M., and Holmes, K.K. (2012). Transactional sex in the fishing communities along Lake Victoria, Kenya: a catalyst for the spread of HIV. African journal of AIDS research: AJAR 11, 9-15.

[13]. MRC U. (2008). Developing and evaluating complex interventions: new guidance. London: Medical Research Council.

[14]. Luo, H., Liang, X., Chen, J., Yang, X.B., Jiang, J.J., Deng, W., Zou, Y.F., Wei, B., Zhang, Z.Y., Liu, Z.H., and Liang, H. (2011). [Acceptability of male circumcision among male miners in Baise of Guangxi]. Zhongguo Yi Xue Ke Xue Yuan Xue Bao 33, 313-317.

[15]. Program, N.T. (2013). Health effects of low-level lead evaluation. Research Triangle Park, NC: US Department of Health and Human Services, National Toxicology Program; 2013. Available at http://ntp. niehs.nih.gov/go/36443. 
[16]. Sahlu, T., Agonafir, A.T., and Tsegaye, T.A. (1998). Factors associated with attendance at HIV post-test counselling in Ethiopia. XII World AIDS Conference; Geneva. June-July 1998; abstract 33280.

[17]. UNAIDS (2007). Male circumcision: global trends and determinants of prevalence, safety and acceptability Geneva: World Health Organisation; 2007. Avaiable: http://whqlibdoc.who.int/publications/2007/9789241596169_eng.pdf. UNAIDS.

\section{Tables}

Table 1. Demographic characteristics of the study participants

\begin{tabular}{|c|c|c|c|c|c|}
\hline & & $\begin{array}{l}\text { Ndhiwa } \\
\text { Sub- } \\
\text { County }\end{array}$ & $\begin{array}{l}\text { Rachuonyo } \\
\text { North Sub- } \\
\text { County }\end{array}$ & $\begin{array}{l}\text { Suba } \\
\text { South } \\
\text { Sub- } \\
\text { County }\end{array}$ & $P$-value \\
\hline \multirow[t]{5}{*}{ Marital status } & Divorced & $2(1.4 \%)$ & $0(0.0 \%)$ & $\begin{array}{l}1 \\
(0.7 \%)\end{array}$ & 0.041 \\
\hline & Married & $99(69.7 \%)$ & $80(58.0 \%)$ & $\begin{array}{l}90 \\
(64.7 \%)\end{array}$ & \\
\hline & Separated & $2(1.4 \%)$ & $2(1.4 \%)$ & $\begin{array}{l}1 \\
(0.7 \%)\end{array}$ & \\
\hline & Single & $32(22.5 \%)$ & $54(39.1 \%)$ & $\begin{array}{l}46 \\
(33.1 \%)\end{array}$ & \\
\hline & Widowed & $7(4.9 \%)$ & $2(1.4 \%)$ & $1(0.7 \%)$ & \\
\hline \multirow[t]{5}{*}{ Religion } & None & $12(8.5 \%)$ & $4(2.9 \%)$ & $\begin{array}{l}3 \\
(2.2 \%)\end{array}$ & 0.001 \\
\hline & Muslim & $3(2.1 \%)$ & $1(0.7 \%)$ & $\begin{array}{l}4 \\
(2.9 \%)\end{array}$ & \\
\hline & $\begin{array}{l}\text { Other } \\
\text { Christians }\end{array}$ & $54(38.0 \%)$ & $50(36.2 \%)$ & $\begin{array}{l}33 \\
(23.7 \%) \\
\end{array}$ & \\
\hline & Protestant & $24(16.9 \%)$ & $47(34.1 \%)$ & $\begin{array}{l}40 \\
(28.8 \%)\end{array}$ & \\
\hline & $\begin{array}{l}\text { Roman } \\
\text { Catholic }\end{array}$ & $49(34.5 \%)$ & $36(26.1 \%)$ & $\begin{array}{l}59 \\
(42.4 \%)\end{array}$ & \\
\hline \multirow[t]{11}{*}{ Occupation } & Blacksmith & $0(0.0 \%)$ & $0(0.0 \%)$ & $\begin{array}{l}1 \\
(0.7 \%)\end{array}$ & $<0.0001$ \\
\hline & Jua Kali & $1(0.7 \%)$ & $1(0.7 \%)$ & $\begin{array}{l}4 \\
(2.9 \%)\end{array}$ & \\
\hline & $\begin{array}{l}\text { Not } \\
\text { Working }\end{array}$ & $17(12.0 \%)$ & $26(18.8 \%)$ & $\begin{array}{l}24 \\
(17.3 \%)\end{array}$ & \\
\hline & $\begin{array}{l}\text { Paid } \\
\text { Employment }\end{array}$ & $8(5.6 \%)$ & $13(9.4 \%)$ & $\begin{array}{l}14 \\
(10.1 \%)\end{array}$ & \\
\hline & Priests & $1(0.7 \%)$ & $0(0.0 \%)$ & $\begin{array}{l}0 \\
(0.0 \%)\end{array}$ & \\
\hline & Student & $1(0.7 \%)$ & $6(4.3 \%)$ & $\begin{array}{l}2 \\
(1.4 \%)\end{array}$ & \\
\hline & $\begin{array}{l}\text { Self- } \\
\text { Employed }\end{array}$ & $0(0.0 \%)$ & $0(0.0 \%)$ & $\begin{array}{l}3 \\
(2.2 \%)\end{array}$ & \\
\hline & Boda Boda & $2(1.4 \%)$ & $2(1.4 \%)$ & $\begin{array}{l}0 \\
(0.0 \%)\end{array}$ & \\
\hline & Carpentry & $0(0.0 \%)$ & $1(0.7 \%)$ & $\begin{array}{l}0 \\
(0.0 \%)\end{array}$ & \\
\hline & $\begin{array}{l}\text { Casual } \\
\text { Labourer }\end{array}$ & $34(23.9 \%)$ & $56(40.6 \%)$ & $\begin{array}{l}34 \\
(24.5 \%)\end{array}$ & \\
\hline & Contractor & $0(0.0 \%)$ & $0(0.0 \%)$ & 1 & \\
\hline
\end{tabular}


DOI: $10.21522 /$ TIJPH.2013.06.03.Art002

ISSN: $2520-3134$

\begin{tabular}{|c|c|c|c|c|c|}
\hline & & & & $(0.7 \%)$ & \\
\hline & Driver & $1(0.7 \%)$ & $0(0.0 \%)$ & $\begin{array}{l}0 \\
(0.0 \%)\end{array}$ & \\
\hline & Farming & $76(53.5 \%)$ & $26(18.8 \%)$ & $\begin{array}{l}53 \\
(38.1 \%)\end{array}$ & \\
\hline & Fishing & $0(0.0 \%)$ & $7(5.1 \%)$ & $\begin{array}{l}3 \\
(2.2 \%)\end{array}$ & \\
\hline & $\begin{array}{l}\text { Gold } \\
\text { Mining }\end{array}$ & $1(0.7 \%)$ & $0(0.0 \%)$ & $\begin{array}{l}0 \\
(0.0 \%)\end{array}$ & \\
\hline \multirow[t]{5}{*}{$\begin{array}{l}\text { Monthly } \\
\text { Income } \\
\end{array}$} & $\begin{array}{l}10,000- \\
20,000\end{array}$ & $32(22.5 \%)$ & $27(19.6 \%)$ & $\begin{array}{l}22 \\
(15.8 \%)\end{array}$ & 0.004 \\
\hline & $\begin{array}{l}>20,000- \\
50,000\end{array}$ & $6(4.2 \%)$ & $13(9.4 \%)$ & $\begin{array}{l}5 \\
(3.6 \%)\end{array}$ & \\
\hline & $<10,000$ & $95(66.9 \%)$ & $77(55.8 \%)$ & $\begin{array}{l}101 \\
(72.7 \%)\end{array}$ & \\
\hline & $>50,000$ & $4(2.8 \%)$ & $1(0.7 \%)$ & $\begin{array}{l}2 \\
(1.4 \%)\end{array}$ & \\
\hline & None & $5(3.5 \%)$ & $20(14.5 \%)$ & $\begin{array}{l}9 \\
(6.5 \%) \\
\end{array}$ & \\
\hline \multirow[t]{2}{*}{ Resident } & Rural & $\begin{array}{l}124 \\
(87.3 \%)\end{array}$ & $129(93.5 \%)$ & $\begin{array}{l}131 \\
(94.2 \%)\end{array}$ & 0.071 \\
\hline & Urban & $18(12.7 \%)$ & $9(6.5 \%)$ & $\begin{array}{l}8 \\
(5.8 \%)\end{array}$ & \\
\hline
\end{tabular}

Table 2. Access to VMMC and VCT in the different sub-counties in homa bay county

\begin{tabular}{|l|l|l|l|l|l|}
\hline & & $\begin{array}{l}\text { Ndhiwa } \\
\text { Sub-County }\end{array}$ & $\begin{array}{l}\text { Rachuonyo } \\
\text { North Sub- } \\
\text { County }\end{array}$ & $\begin{array}{l}\text { Suba South } \\
\text { Sub-County }\end{array}$ & $P$-value \\
\cline { 1 - 5 } $\begin{array}{l}\text { Accessed } \\
\text { VCT Service }\end{array}$ & Yes & $78(54.9 \%)$ & $116(84.1 \%)$ & $97(69.8 \%)$ & $<0.0001$ \\
\hline & No & $64(45.1 \%)$ & $22(15.9 \%)$ & $42(30.2 \%)$ & \\
\cline { 1 - 3 } & Yes & $5(3.5 \%)$ & $1(0.7 \%)$ & $15(10.8 \%)$ & $<0.0001$ \\
\hline & No & $137(96.5 \%)$ & $137(99.3 \%)$ & $124(89.2 \%)$ & \\
\hline
\end{tabular}

Analyses performed using Chi-square test. $P$-values in bold are significant at the $P \leq 0.05$ cut-off.

Table 3. Factors affecting access to VMMC, VCT and socio-demographic characteristics in homa-bay county

\begin{tabular}{|c|c|c|c|c|c|c|c|}
\hline \multirow[t]{2}{*}{ Characteristic } & & \multicolumn{3}{|c|}{ Access to VCT services } & \multicolumn{3}{|c|}{ Access to VMMC } \\
\hline & & $\begin{array}{l}\text { Yes, } \\
\text { n(\%) }\end{array}$ & $\begin{array}{l}\text { No, n } \\
(\%)\end{array}$ & $\begin{array}{l}P \text { - } \\
\text { value }\end{array}$ & $\begin{array}{l}\text { Yes, } \\
\text { n(\%) }\end{array}$ & $\begin{array}{l}\text { No, n } \\
(\%)\end{array}$ & $\begin{array}{l}P \text { - } \\
\text { value }\end{array}$ \\
\hline \multirow[t]{5}{*}{ Marital status } & Divorced & $2(0.7)$ & $1(0.8)$ & \multirow[t]{5}{*}{0.228} & $0(0.0)$ & $3(0.8)$ & \multirow[t]{5}{*}{0.328} \\
\hline & Married & $\begin{array}{l}194 \\
(66.7)\end{array}$ & $\begin{array}{l}75 \\
(58.6)\end{array}$ & & $\begin{array}{l}16 \\
(76.2)\end{array}$ & $\begin{array}{l}253 \\
(63.6)\end{array}$ & \\
\hline & Separated & $5(1.7)$ & $0(0.0)$ & & $1(4.8)$ & $4(1.0)$ & \\
\hline & Single & $84(28.9)$ & $\begin{array}{l}48 \\
(37.5)\end{array}$ & & $4(19.0)$ & $\begin{array}{l}128 \\
(32.2)\end{array}$ & \\
\hline & Widowed & $6(2.1)$ & $4(3.1)$ & & $0(0.0)$ & $10(2.5)$ & \\
\hline \multirow[t]{3}{*}{ Religion } & None & $9(3.1)$ & $10(7.8)$ & \multirow[t]{3}{*}{0.182} & $1(4.8)$ & $18(4.5)$ & \multirow[t]{3}{*}{0.375} \\
\hline & Muslim & $7(2.4)$ & $1(0.8)$ & & $0(0.0)$ & $8(2.0)$ & \\
\hline & Other & $93(32.0)$ & 44 & & $3(14.3)$ & 134 & \\
\hline
\end{tabular}



Volume 6, Issue 3, Sep 2018

\begin{tabular}{|c|c|c|c|c|c|c|c|}
\hline & Christians & & $(34.4)$ & & & (33.7) & \\
\hline & Protestant & $80(27.5)$ & $\begin{array}{l}31 \\
(24.2)\end{array}$ & & $7(33.3)$ & $\begin{array}{l}104 \\
(26.1)\end{array}$ & \\
\hline & $\begin{array}{l}\text { Roman } \\
\text { Catholic }\end{array}$ & $\begin{array}{l}102 \\
(35.1)\end{array}$ & $\begin{array}{l}42 \\
(32.8)\end{array}$ & & $\begin{array}{l}10 \\
(47.6)\end{array}$ & $\begin{array}{l}134 \\
(33.7)\end{array}$ & \\
\hline \multirow[t]{15}{*}{ Occupation } & Blacksmith & $1(0.3)$ & $0(0.0)$ & \multirow[t]{15}{*}{0.163} & $0(0.0)$ & $1(0.3)$ & \multirow[t]{15}{*}{0.905} \\
\hline & Jua Kali & $5(1.7)$ & $1(0.8)$ & & $0(0.0)$ & $6(1.5)$ & \\
\hline & $\begin{array}{l}\text { Not } \\
\text { Working }\end{array}$ & $38(13.1)$ & $\begin{array}{l}29 \\
(22.7)\end{array}$ & & $3(14.3)$ & $\begin{array}{l}64 \\
(16.1) \\
\end{array}$ & \\
\hline & $\begin{array}{l}\text { Paid } \\
\text { Employment }\end{array}$ & $28(9.6)$ & $7(5.5)$ & & $3(14.3)$ & $32(8.0)$ & \\
\hline & Priests & $0(0.0)$ & $1(0.8)$ & & $0(0.0)$ & $1(0.3)$ & \\
\hline & Student & $7(2.4)$ & $2(1.6)$ & & $0(0.0)$ & $9(2.3)$ & \\
\hline & $\begin{array}{l}\text { Self- } \\
\text { Employed }\end{array}$ & $3(1.0)$ & $0(0.0)$ & & $0(0.0)$ & $3(0.8)$ & \\
\hline & Boda Boda & $2(0.7)$ & $2(1.6)$ & & $1(4.8)$ & $3(0.8)$ & \\
\hline & Carpentry & $1(0.3)$ & $0(0.0)$ & & $0(0.0)$ & $1(0.3)$ & \\
\hline & $\begin{array}{l}\text { Casual } \\
\text { Labourer }\end{array}$ & $88(30.2)$ & $\begin{array}{l}36 \\
(28.1) \\
\end{array}$ & & $8(38.1)$ & $\begin{array}{l}116 \\
(29.1)\end{array}$ & \\
\hline & Contractor & $1(0.3)$ & $0(0.0)$ & & $0(0.0)$ & $1(0.3)$ & \\
\hline & Driver & $1(0.3)$ & $0(0.0)$ & & $0(0.0)$ & $1(0.3)$ & \\
\hline & Farming & $\begin{array}{l}105 \\
(36.1) \\
\end{array}$ & $\begin{array}{l}50 \\
(39.1) \\
\end{array}$ & & $5(23.8)$ & $\begin{array}{l}150 \\
(37.7)\end{array}$ & \\
\hline & Fishing & $10(3.4)$ & $0(0.0)$ & & $1(4.8)$ & $9(2.3)$ & \\
\hline & $\begin{array}{l}\text { Gold } \\
\text { Mining }\end{array}$ & $1(0.3)$ & $0(0.0)$ & & $0(0.0)$ & $1(0.3)$ & \\
\hline \multirow[t]{5}{*}{$\begin{array}{l}\text { Monthly } \\
\text { Income }\end{array}$} & $\begin{array}{l}10,000- \\
20,000\end{array}$ & $60(20.6)$ & $\begin{array}{l}21 \\
(16.4)\end{array}$ & \multirow[t]{5}{*}{0.234} & $0(0.0)$ & $\begin{array}{l}81 \\
(20.4) \\
\end{array}$ & \multirow[t]{5}{*}{0.054} \\
\hline & $\begin{array}{l}>20,000- \\
50,000\end{array}$ & $20(6.9)$ & $4(3.1)$ & & $2(9.5)$ & $22(5.5)$ & \\
\hline & $<10,000$ & $181(62.2)$ & $\begin{array}{l}92 \\
(71.9)\end{array}$ & & $\begin{array}{l}18 \\
(85.7)\end{array}$ & $\begin{array}{l}255 \\
(64.1)\end{array}$ & \\
\hline & $>50,000$ & $4(1.4)$ & $3(2.3)$ & & $1(4.8)$ & $6(1.5)$ & \\
\hline & None & $26(8.9)$ & $8(6.3)$ & & $0(0.0)$ & $34(8.5)$ & \\
\hline \multirow[t]{2}{*}{ Resident } & Rural & $\begin{array}{l}266 \\
(91.4) \\
\end{array}$ & $\begin{array}{l}118 \\
(92.2) \\
\end{array}$ & \multirow[t]{2}{*}{0.791} & $\begin{array}{l}18 \\
(85.7) \\
\end{array}$ & $\begin{array}{l}366 \\
(92.0) \\
\end{array}$ & \multirow[t]{2}{*}{0.313} \\
\hline & Urban & $25(8.6)$ & $10(7.8)$ & & $3(14.3)$ & $32(8.0)$ & \\
\hline
\end{tabular}

Analyses performed using Chi-square test. $P$-values in bold are significant at the $P \leq 0.05$ cut-off. 